\title{
A animação educativa no desenvolvimento pessoal e social de futuros formadores: uma abordagem centrada na prática teatral
}

\author{
Maria José dos Santos Cunha \\ Universidade de Trás-os-Montes e Alto Douro, Portugal
}

\begin{abstract}
Resumo
Neste artigo procuramos focalizar, a partir de um trabalho realizado em contexto extra-curricular com formandos das Licenciaturas de Educação de Infância e de Professores do $1^{\circ}$ Ciclo do Ensino Básico, o papel de um objecto de estudo ainda pouco explorado num contexto de formação inicial, o da animação educativa aliada a práticas teatrais, descrevendo de forma sintética o processo que a ele conduziu, apresentando os resultados e apreciando os seus valores.
\end{abstract}

Palavras-chave

Desenvolvimento; Formação; Animação; Práticas

\section{Introdução}

O trabalho que agora apresentamos aborda o Desenvolvimento Pessoal e Social de futuros formadores a partir de uma perspectiva prática de Animação Educativa, trabalho levado a cabo através da implementação de uma oficina de expressão dramática e teatro, uma vez que é sua intenção abordar este objecto de estudo pelo lado do fazer educativo. Propõe-se, nesse sentido, relatar um estudo, desenvolvido em contexto extracurricular, com um grupo constituído por vinte e cinco alunos finalistas das Licenciaturas em Educação de Infância e Professores do 1ํㅡㄹ Clo do Ensino Básico da extensão em Chaves da Universidade de Trás-os-Montes e Alto Douro. 
Através do contacto directo com os alunos e das conversas informais que com eles mantivemos, fomo-nos apercebendo que a maioria sentia: dificuldades de adaptação ao ambiente académico; que o relacionamento entre colegas estava cada vez mais fragilizado pela competição diariamente vivida; que existia um vazio e um desânimo, mais ou menos colectivo, que motivava a sua não participação em actividades culturais e provocava neles uma falta de orgulho e de auto-estima; dificuldades durante o estágio e imensos receios em relação às suas práticas no início da carreira profissional.

Foram as razões expostas, aliadas à leitura de algumas obras citadas neste artigo, que fizeram despertar em nós o interesse pela realização deste estudo e crescer a convicção de que a Animação Educativa, especialmente pela motivação que propicia, podia contribuir para o desenvolvimento integral do indivíduo em formação e favorecer o sucesso pedagógico. Baseados nesta convicção decidimos avançar para o estudo como forma de conseguir respostas para a seguinte questão: Como responde a animação educativa, enquanto meio activo de desenvolvimento pessoal e social, num contexto de formação com futuros formadores? Respostas que deveriam confirmar ou infirmar o grau de exequibilidade de um plano de desenvolvimento pessoal e social de educadores/professores em formação, previamente concebido. $O$ estudo assentou na investigação-acção, metodologia com ênfase nas práticas reflexivas, e foi desenhado segundo um plano de investigação em que o formador-investigador se implicou na própria acção de formação investigando-a, para assim a ir melhorando.

Levar a tarefa investigativa a bom porto exigiu socorrermo-nos de instrumentos diversificados tais como: questionários; fichas de auto-avaliação e retrospectivas; observações directas; fichas de avaliação formativa; diário de bordo; entrevistas; registos foto-videográficos e consulta de legislação. Instrumentos que nos permitiram definir o problema, conhecer as opiniões/concepções de profissionais de educação, diagnosticar as expectativas e capacidades dos formandos implicados no estudo, desenhar o plano de intervenção e efectuar a sua avaliação.

Entendemos que um projecto de desenvolvimento pessoal e social de futuros formadores é uma prática educativa que deve desenvolver-se e basear-se em métodos activos, facilitadores da aquisição de atitudes, que propiciem esse desenvolvimento e, ao mesmo tempo, induzam a participação 
de todos em todas as fases do mesmo, certos de que a formação inicial é o primeiro passo para promover essas potencialidades nos formandos.

\section{Animação Educativa e desenvolvimento pessoal e social na formação inicial: enquadramento teórico do estudo}

\section{Desenvolvimento pessoal e social e educação}

A valorização do ser humano e a formação pessoal e social de crianças e jovens foi sempre uma das preocupações que acompanhou a educação ao longo da sua história. A justificá-lo, numa breve análise retrospectiva pelo século $X X$, são de salientar os seguintes aspectos: a valorização que a 1ํㅡ República quis dar à formação cívica ao incluí-la no currículo, em substituição da religião moral e católica e à qual Adolfo Lima (citado por Pintassilgo, 1998: 140) se refere da seguinte forma: "a educação cívica consiste no ensino de uma série ou séries de puras abstracções, à frente das quais estão os termos pátria, estado, deveres do cidadão, direitos destes, eleições, voto"; a promulgação da Lei no 5 de 25 de Julho de 1973, com um conjunto de medidas muito próximas do que hoje entendemos por formação pessoal e social; a Lei no 46/86, Lei de Bases do Sistema Educativo, que estabelece o quadro geral do sistema educativo e cujo imperativo é a introdução de uma dimensão ética e cívica que prepare crianças e jovens para o exercício da cidadania, entendida por Jorge Sampaio (citado por Paixão, 2000: 3) como "responsabilidade perante nós e perante os outros, consciência de deveres e direitos, impulso para a solidariedade e para a participação, é sentido de comunidade e de partilha, é insatisfação perante o que é injusto ou o que está mal, é vontade de aperfeiçoar, de servir, é espírito de inovação, de audácia, de risco, é pensamento que age e acção que se pensa", e que estimule nas crianças e jovens o seu desenvolvimento pessoal e social, o que pressupõe, na opinião de Praia, "desde logo acercar o aluno do mundo em que tem de viver e das suas complexas inter-relações, bem assim como pressupõe abandonar as tradicionais metodologias memorístico-repetitivas. $O$ que nos conduzirá ao objectivo primordial - estimular valores, desenvolver atitudes" (Praia, 1991: 15); a inclusão da Área de Formação Pessoal e Social nos planos curriculares do ensino básico, operacionalização que ocorreu com a publicação do Decreto-Lei no 286/89 de 29 de Agosto; a Lei-Quadro da 
Educação Pré-Escolar, Lei 5/97 de 10 de Fevereiro que menciona no seu artigo décimo que os objectivos da educação pré-escolar são o de promover o desenvolvimento pessoal e social; o de estimular o desenvolvimento global no respeito pelas características individuais e o de desenvolver a expressão e a comunicação de sensibilidade estética e de compreensão do mundo; a Reorganização Curricular do Ensino Básico consagrada no Decreto-Lei n.o 6/2001 de 18 de Janeiro, que serve de enquadramento legal a uma nova forma de pensar o ensino e define os princípios orientadores a que deve obedecer a organização e gestão curricular do ensino básico. A Educação veio assim adquirindo importância fundamental no e para o Desenvolvimento Pessoal e Social, embora com o fim do século XX se tenha instalado um certo fatalismo que persiste no começo do século actual, podendo mesmo dizer-se que "vivemos um período em que as instituições educativas tradicionais estão a perder a capacidade de transmitir eficazmente valores e modelos culturais de coesão social" (Barbosa, 2001: 82), o que exige uma mudança profunda das estruturas e dinâmicas de funcionamento, quer da escola quer das relações entre educadores/professores e educandos, quer mesmo dos educadores/ /professores com a comunidade educativa.

\subsection{Escola e família. Problemas e desafios}

No final do século $X X$ assiste-se à perda de relevância do papel da família na educação das crianças. A este respeito Fonseca afirma que "o eclipse progressivo da família neste final do século $X X$ abriu um vazio nesta matéria, que a escola se esforça por preencher" (2001: 13) ao desempenhar, para além do seu papel educativo e formativo, o papel que à família compete.

Várias razões estão na origem desta demissão da família na transmissão de saberes (que são referências e valores a seguir) e no vazio que se criou na estrutura familiar, nomeadamente: a falta de tempo ou a rápida mudança da posição da mulher, que passou, tal como o homem, a trabalhar fora de casa; a falta de vontade, o bem-estar e o conforto, o hedonismo (porque é cansativo estar sempre a repetir regras de conduta) e uma crise a nível de afectos que a família vive e faz com que nomeadamente os pais se tenham vindo a demitir do seu papel de pais. De facto, um dos aspectos em que a desatenção dos pais para com os filhos é notória é a educação para os valores. A este propósito Savater é de opinião que "há que 
desenvolver uma crítica severa face ao modo como ao adultos (pais, famílias) têm vindo a desistir da tarefa de assumir as suas responsabilidades relativamente aos mais novos nesta matéria" (1997: 18). Por outro lado, e não menos importante, é ter presente que "os educadores e os pais que noutro tempo eram o ponto de referência das sociedades não receberam preparação para enfrentarem a nova situação" (Hernando, 1999: 31), do que decorre a necessidade de se desenvolver na escola uma variedade de experiências adequadas à preparação para a vivência na sociedade actual.

Em Portugal o discurso entre escola e família é fechado, razão porque Bolívar considera que "assumir isoladamente a tarefa educativa, tendo em consideração que a falta de vínculos de articulação entre família, escola e meios de comunicação, constitui uma fonte de tensões, de mal estar docente e de novos desafios" (2000: 165). Cabe portanto à escola mudar esta situação, através da motivação dos pais para ela, uma vez que a eles compete, de acordo com a Lei 30/2002 de 20 de Dezembro, dirigir a educação dos filhos, acompanhar a sua vida escolar e cooperar com os educadores/professores no desempenho da sua missão pedagógica.

\subsection{O educador - professor como actor de mudança}

Tendo em conta os actuais planos curriculares facilmente se compreende o esforço dos educadores/professores na promoção dos meios mais diversos para se criarem ambientes e situações favoráveis à aprendizagem, à inter-relação, à autonomia e que, em simultâneo, possibilitem despertar nos alunos curiosidade e interesse. Relativamente ao papel que ao educador/professor compete, Soares afirma que "não é só o de transmissão de conhecimentos - é também e sobretudo o de despertar a criatividade, a capacidade crítica, o de ser intermediário entre o aluno pessoa, indivíduo - e a realidade que o cerca global e colectiva" (1997: 18). Terem em consideração os conteúdos afectivos, tal como têm os cognitivos, devem ser os seus objectivos e "tarefa de todos os agentes educativos, ou pelo menos de todos aqueles verdadeiramente interessados em educar para formar pessoas mais capazes, mais autónomas e mais felizes" (Agústi, 1993: 85), porque é neste intercâmbio de saberes e afectos que o processo de formação se desenvolve e consolida. 
Ensinar não é fácil e o educador/professor "tem de ser um bom animador, motivando os seus alunos para conteúdos e actividades que os interessam, a fim de neles se empenharem. Aquilo que de alguma forma nos interessa pode transformar-se em fonte de prazer e a aprendizagem lúdica aparece naturalmente" (Cabral, 2001: 243). Deve gostar de criar e experimentar soluções diferentes e ter em mente que a sua missão não é apenas a de instruir, mas também a de educar e socializar, porque "só existe saber na invenção, na reinvenção, na busca inquieta, impaciente, permanente, que os homens fazem no mundo, com o mundo e com os outros" (Freire, 1972: 66), tarefa que é talvez a mais difícil e menos praticada.

\section{A Animação Educativa como estratégia de desenvolvimento pessoal e social}

A Animação Educativa é uma dimensão básica da Animação Sociocultural. Na esteira de Ventosa (1997: 44) é "através de três modalidades básicas: a cultural (animação cultural), a social (animação social) e a educativa (animação educativa)" que a Animação Sociocultural leva a cabo a sua missão, que é a de se ligar intimamente ao desenvolvimento do indivíduo e da comunidade em que este se insere. Neste trabalho fazemos especial referência à Animação Educativa que, pelas suas características que "potenciam e desenvolvem atitudes de formação pessoal e grupal adaptadas às contínuas mudanças" (Ucar, 1992: 41), nos parece especialmente adequada para a intervenção que pretendemos levar a cabo. E porque, no entender de Cunha, ela é "um meio excepcional para a alteração do comportamento e de mentalidades que persistem, designadamente quando promove valores de solidariedade, de entreajuda e auto-estima entre as pessoas, quando estimula a capacidade dos participantes para transformar ideias em projectos" (2000: 45), começa a ser-lhe dado protagonismo em projectos educativos, na medida em que apresenta inúmeras vantagens no campo da educação.

Contribuir para a formação de uma auto-estima forte é o objectivo principal da Animação Educativa, o que é particularmente relevante na medida que "quanto mais positiva é a nossa auto-estima mais preparados estamos para enfrentar as adversidades e resistir às frustrações, mais possibilidades temos de ser criativos no nosso trabalho e de encontrar mais 
oportunidades de estabelecer relações enriquecedoras, mais dispostos nos sentimentos para tratar os outros com respeito e mais satisfação encontramos pelo simples facto de vivermos" (Martínez, 2001: 95). A sua força reside, como refere Ventosa, no facto de que "enquanto a educação necessita normalmente de motivações externas para se manter como tal, a animação encontra em si mesma a sua própria motivação" (1995: 25), o que faz dela uma ferramenta privilegiada ao serviço da construção da pessoa.

Confrontada com a missão de formar o homem cidadão, a escola actual é o lugar por excelência para levar a cabo projectos de animação, uma vez que esta é "um instrumento nas mãos dos grupos humanos que a utilizam para facilitar aos seus membros o acesso a determinados valores, conhecimentos, habilidades e estratégias que se consideram importantes" (Quintas, 2002: 105) e um modo fundamental de transformação da acção educativa. Cabe por isso à escola possibilitar uma educação conjugada com a animação, onde as práticas orientadas para o desenvolvimento pessoal e social "ganhem verdadeiro contexto na sociedade e sobretudo nas escolas e na formação das crianças e do próprio adulto, pois trata-se de trazer de volta os conteúdos da verdadeira essência humana, onde o cognitivo, o emotivo, o físico e o espiritual ganham contexto como partes de um equilíbrio e onde a sensibilidade, o sentimento, a atenção, o respeito por si, pelos outros e pela vida são assumidos com responsabilidade e logo em liberdade, a verdadeira liberdade que se adquire por ser um verdadeiro ser humano" (Beltrán, 2000: 142).

Esperamos, pelas razões expostas, poder extrair deste processo de investigação respostas favoráveis à nossa questão inicial: "Como responde a animação educativa, enquanto meio activo de desenvolvimento pessoal e social, num contexto de formação com futuros formadores?", que permitam utilizá-la como complemento do desenvolvimento pessoal e social dos futuros educadores/professores, de forma a desenvolver neles, ou a trazer à superfície princípios e valores fundamentais para que se estabeleça uma dimensão humana no processo de ensino-aprendizagem e na promoção de capacidades de invenção e realização individual e grupal, que contribuam para a criação do novo paradigma educativo que a actual sociedade requer. 


\subsection{A Expressão Dramática e o Teatro. Contributos para a mudança de atitudes}

Entendidas como linguagens teatrais, com abordagens e formas de expressão diferentes, mas que apesar disso se completam porque são aspectos da mesma matéria, a Expressão Dramática e o Teatro podem contribuir para que a experiência que temos da vida seja compreendida, activada ou mesmo transformada. No entender de Ucar, o que diferencia o Teatro da Expressão Dramática é que "o primeiro dá ênfase ao espectáculo, como obra dramática acabada, apta a ser vista. O espectáculo será pois, elemento capital para se poder falar de teatro. A segunda, pelo contrário, dá ênfase à realização da acção propriamente dita, no processo de representação. Assim, o primeiro define-se pelo seu produto, enquanto que a segunda se defina pelo processo" (1992: 34).

O facto destas formas de expressão poderem originar práticas facilitadoras nos processos de alteração de modos de ser, estar e comunicar (capazes de provocar mudanças que garantam e estimulem a iniciativa, a participação activa, a colaboração, a responsabilidade de cada um e de todos no processo do seu próprio desenvolvimento), ganhando desta forma "o direito de intervir e de intervir com capacidades de decisão" (Nóvoa, 1993: 12), configuram-nas como interessante recurso ao nível da educação, formação e desenvolvimento de capacidades pessoais, podendo assim fertilizar boa parte das experiências que urge levar a cabo nas nossas instituições de formação. De facto, quer a Expressão Dramática quer o Teatro revelam-se, tal como "um fermento de vida anímica que se transfere e irradia, impregnando o todo da actividade espiritual" (Grácio, 1995: 100), como práticas fecundas em processos de desenvolvimento pessoal e social, na medida em que remetem para a criatividade, para a reflexão na acção, para a valorização dos tempos de retroacção, para uma formação baseada na experiência e em vivências pessoais. Razões que nos impeliram a considerar as suas potencialidades num contexto inexplorado de desenvolvimento pessoal e social de futuros formadores através da animação Educativa, com o objectivo de ajudar estes profissionais de educação a caminhar em direcção à mudança.

\section{Novas realidades na formação inicial}

Num mundo em que as transformações se sucedem a um ritmo vertiginoso e no qual se acentuam as pressões sociais, a educação enfrenta 
desafios permanentemente. A este propósito, Grilo é de opinião que "aquilo que formos capazes de construir e consolidar no próximo decénio vai seguramente condicionar de forma marcante o futuro daqueles que nos vão suceder, e que são os jovens de hoje" (2002: 58), razão para que seja urgente um outro olhar sobre a educação e a formação por parte de todos os que de alguma forma têm a ver com estas áreas. E porque "o novo brota sem cessar. Nunca podemos prever como se apresenta, mas devemos contar com a sua chegada" (Morin, 2001: 35), a formação (como pedra angular da reforma do sistema educativo) tem de assumir uma importância acrescida, sobretudo ao nível das práticas de ensino que devem estimular e valorizar o pensamento crítico dos educandos e ser apoiadas por formadores com formação pessoal sólida e capacidade de se adaptarem a diferentes situações, embora Beltrão \& Nascimento chamem a atenção para o facto de que se não devem propor metas inatingíveis, porque "o óptimo é inimigo do bom" (2000: 51). Nesta mudança torna-se necessário a colaboração de todos, em especial dos educadores/professores que têm de colaborar activamente abrindo-se a ela, aprendendo a gerir conflitos, melhorando a sua auto-estima e autoconceito e desenvolvendo-se pessoal e socialmente, na medida em que "quando estão criadas as condições do desenvolvimento fundamental do homem, revela-se o seu real crescimento na capacidade plena de ver, observar, experimentar, reflectir, ponderar, pensar, criticar, questionar" (Dias, 2002: 19). Aspectos que justificam, por si só, o investimento em estratégias de formação inovadoras e práticas motivadoras, flexíveis e diversificadas.

Esta necessidade de na formação inicial se desenvolver mais a área de formação pessoal coloca-se, segundo Barbosa, porque "o desenvolvimento pessoal e social (centrado na aprendizagem e na autonomia e na preparação para o exercício activo da cidadania) configura-se e perfilase desde já como meio adequado para abordar esses problemas de inserção na vida activa" (1999: 81).

Os fenómenos de mudança não podem "ser ignorados pela educação e formação, porquanto educar não é preparar as novas gerações para a estabilidade, mas para acompanharem o fluir do tempo. Por isso o grande desafio dos sistemas educativos e formativos é o de se assumirem em reforma permanente" (Simão, Santos \& Costa, 2002: 384). O objectivo central da formação que se pretende deve, assim, desenvolver nos futuros formadores qualidades pessoais, saberes e capacidades, que Ihes permitam responder, no presente e no futuro, às necessidades dos alunos e da 
sociedade. Como refere Alcántara (1998: 10), "a formação de atitudes é a única maneira de preparar e capacitar o jovem para a vida" e consegui-lo exige, na opinião de Alves (2003: 1), "mudar o diagnóstico, mudar de receita, mudar de terapia. Ser simultaneamente mais sensível, mais lúcido, mais humilde. E mais exigente nas várias esferas e dimensões do social. É aí que é preciso centrar a reforma".

Num tempo em que as universidades se batem por uma procura contínua de qualidade, de que faz parte uma formação inicial de educadores/professores mais centrada na educação global, consideramos ser a altura ideal para apostar em projectos práticos de intervenção, que apontem, de modo fundamentado, formas e estratégias motivadoras que coadjuvem (tal como a Animação Educativa) no atingir essa formação, para que o formador seja um ser que sabe intervir de forma adequada, eficaz e completa, em relação aos objectivos educacionais.

\subsection{Oficina de Expressão Dramática e Teatro. Porta aberta ao desenvolvimento pessoal e social}

Como recurso didáctico, uma oficina de expressão dramática e teatro pode considerar-se como local onde se vive "todo estímulo do trabalho de grupo, se aprende o valor da entreajuda, se toma consciência do valor da responsabilidade pessoal (em cada tarefa individual) e da responsabilidade colectiva (na execução dos trabalhos que é necessário levar a cabo com o esforço comum)" (Jacinto, 1991: 19-20). Espaço por excelência de formação, nela se pode desenvolver todo um conjunto de actividades teórico-práticas com vista à realização de determinados objectivos e criar alternativas de solução para determinados problemas. No dizer de Fonseca (1994: 15-16), “o ensino meramente teórico dos deveres sociais reveste-se de pouco ou nenhum interesse [...] tornando-se urgente experimentar itinerários pedagógicos que salientem o papel activo dos alunos, estimulando iniciativas que promovam a responsabilização, impulsionando o contacto com 0 diferente, desafiando os equilíbrios estabelecidos e promovendo a emergência de um pensamento cada vez mais rico e de uma acção cada vez mais consciente". E porque "os saberes e competências adquiridos através da formação inicial não são mais suficientes para enfrentar as novas exigências da sociedade em mudança" (Fernandes e outros, 2001: 41), há que despertar 
os jovens formandos para a prática teatral, porque esta "reúne todos os ingredientes necessários para ser um centro de interesses incrivelmente rico em conteúdos. Além de tudo o mais, o educador pode conseguir um conjunto de objectivos impossíveis ou, pelo menos, difíceis de alcançar com outro tipo de metodologia" (Laguna, 1995: 10), sendo por isso ideal para que passem dos conteúdos à prática e trabalhem para um objectivo comum, a educação.

\section{Posicionamento de Profissionais de Educação face ao papel da Animação Educativa no desenvolvimento pessoal e social de futuros formadores}

\section{Um estudo de concepções e opiniões}

Como forma de obter uma visão mais ampla sobre a problemática em análise, entendemos ser importante auscultar a opinião dos educadores/professores cooperantes com a UTAD nas práticas pedagógicas. Pretendíamos conhecer como se posicionavam face ao objecto de estudo, que representações possuíam na área, o valor que atribuíam à formação integral da criança/pessoa em formação e se anteviam na Animação Educativa contributos positivos para a formação integral dos futuros formadores e dos seus próprios educandos.

Constituímos para o efeito uma amostra representativa destes profissionais de educação, aos quais passámos um inquérito por questionário, com o formato do tipo escala Likert, constituído por oitenta e seis questões fechadas, que funcionou como instrumento de recolha de informação para o estudo que se pretendia levar a cabo. Estruturámos este questionário em quatro grandes blocos: bloco A - Dados Pessoais e Profissionais; bloco B Desenvolvimento Pessoal e Social na Escola; bloco C - Animação Educativa para o Desenvolvimento Pessoal e Social na Escola através da Expressão Dramática e do Teatro; e o bloco D - Animação Educativa através da Expressão Dramática e do Teatro para o Desenvolvimento Pessoal e Social na Formação de Formadores. Aplicado o questionário, procedemos à respectiva análise e tratamento de dados quantitativos que, para maior facilidade, foi efectuado também por blocos.

Através das suas respostas os inquiridos manifestaram comungar de opiniões idênticas às nossas, nomeadamente quando concordam que é 
pertinente formação na área de desenvolvimento pessoal e social dirigida a educadores/professores em formação, que a vertente humana e as relações pessoais são os alicerces em que deverá assentar toda a formação, uma vez que ensinar implica, cada vez mais, ter em conta o desenvolvimento pessoal e social do educando e que, para o efeito, muitos deles não se consideram suficientemente preparados. Concordaram ainda que a Animação Educativa, através da expressão dramática e do teatro, faculta ao educador/professor em formação as condições necessárias ao fortalecimento do seu bem-estar pessoal e social, que o teatro ajuda o formando no desenvolvimento progressivo de condições necessárias à produção de reflexões críticas, à capacidade de reconstrução criativa da realidade e ao desenvolvimento da capacidade de participação social e, ainda, que a formação extra-curricular pode proporcionar aprendizagens significativas.

\section{Diagnóstico dos participantes}

\section{Expectativas e posicionamento dos formandos face à Animação Educativa}

Partindo do princípio que o conhecimento do diagnóstico das necessidades permite um desenho mais completo da intervenção a realizar, "é importante sabermos o que pensam, o que desejam aqueles com quem vamos trabalhar. Através de um simples questionário, de algumas entrevistas, de debates ou de qualquer outro tipo de actividade que nos ocorra, deveremos procurar saber quais são as suas principais preocupações, que temas Ihes interessam, como abordam essa temática, quantos estariam dispostos a participar no projecto e que tipo de participação é possível prever" (Zabalza, 1998: 64).

Neste sentido, considerámos ser útil desenhar e aplicar um inquérito, mediante questionário escrito, a fim de conhecermos o que os formandos pensavam de um contacto directo com a Animação Educativa, a Expressão Dramática e o Teatro. Pretendíamos obter, antes do início da acção pedagógica, dados relativos às suas motivações, interesses, expectativas, necessidades, conhecimentos e experiências, isto é, pretendíamos fazer uma avaliação diagnóstica. O questionário aplicado, uma combinação mista de perguntas abertas e fechadas, foi o instrumento básico que permitiu recolher informação que outros meios não possibilitariam tão facilmente. 


\section{Reflexão sobre o diagnóstico dos participantes}

A avaliação diagnóstica, enquanto primeira recolha de dados e informações sobre os formandos, foi uma etapa importantíssima na identificação do seu perfil, bem como na estruturação da base do nosso plano de acção, na medida em que possibilitou aproximar-mos os nossos pressupostos iniciais da realidade concreta. Ocupou as duas primeiras sessões da oficina e desenvolveu-se através de um conjunto de exercícios técnico-práticos, cooperativos e técnicas teatrais. A primeira sessão foi ocupada com nove exercícios e a segunda com sete. Informou-nos sobre as capacidades, carências e necessidades formativas dos formandos e sugeriunos formas possíveis de conduta. Permitiu, assim, um desenho mais completo da intervenção e disponibilizou um ponto de partida para a planificação das actividades a desenvolver.

\section{Estratégia metodológica}

Neste estudo pretendia-se sobretudo uma metodologia livre, de autodescoberta, que favorecesse o desenvolvimento de capacidades, conhecimentos e atitudes dos futuros formadores, para que possam reflectir nos seus educandos a sua especial forma de ser. Nesse sentido, privilegiamos a Investigação-Acção, metodologia esta de cariz qualitativo. Segundo Bell, esta metodologia consiste "numa abordagem que se revela particularmente atraente para os educadores, devido à sua ênfase prática na resolução de problemas" (1997: 22). Autores como Kemmis \& Mactaggart apresentam-na como "um processo concreto e prático que ajuda os nele implicados a dar forma [...] a perspectivas educativas e melhorar a educação" (1988: 379). Esta metodologia é um processo reflexivo que se desenvolve, segundo os mesmos autores, "seguindo uma espiral introspectiva. Uma espiral de ciclos de planificação, acção (estabelecimento de planos), observação (sistemática), reflexão [...] e logo replanificação, novo passo para a acção, novas observações e reflexões” (Kemmis \& Mactaggart, 1988: 30). Fazia portanto todo o sentido, no trabalho que se pretendia levar a cabo, adoptar esta metodologia, que tem a prática reflexiva como fundo norteador. 


\section{Vectores da Planificação}

\section{Abordagem preliminar}

Planificar ou delinear um plano é prever, de forma sistemática e racional, o conjunto de acções que é necessário levar a cabo na elaboração de determinados objectivos face aos recursos existentes. A essência da planificação é antecipar e prever o futuro, relacionar os meios com os fins e construir um esquema que oriente a acção. A planificação funciona como um processo dinâmico e permanente que, de forma contínua, desencadeia novas aç̧ões e leva a "conjugar a utopia com a realidade, a harmonizar o que é e o que deveria ser, a analisar donde estamos e até onde pretendemos chegar" (Serrano, 1999: 9). E porque a prática enriquece ou modifica a teoria, o investigador deve pôr em acção, nesta fase, os seus conhecimentos teóricos, toda a sua bagagem formativa e as suas inquietações.

Apresentamos, de seguida, a estrutura desenhada para a planificação deste trabalho, que foi distribuída em cinco seç̧ões básicas: as finalidades e objectivos gerais da investigação; a organização da oficina de expressão dramática e teatro; as actividades; a avaliação e, por último, a calendarização.

\subsection{Finalidades e objectivos}

Seleccionar os objectivos não foi tarefa fácil, visto todas as finalidades e objectivos gerais se nos apresentarem como relevantes. Fizemos a escolha tendo em conta variáveis como: o tempo de que dispúnhamos, a natureza dos actores envolvidos e os valores e intenções que nos moviam.

Os objectivos são o primeiro elemento a considerar na altura de elaborar um plano de trabalho com vista à mudança, nele se apresentando como elementos dinâmicos, acções que devemos realizar, sós ou em grupo. Assumem a função de orientadores das actividades, devendo, para que cumpram a sua finalidade, ser elaborados segundo determinados pressupostos como: conduzirem a uma acção transformadora, responderem às necessidades e interesses do grupo objecto de estudo e serem avaliáveis.

$\mathrm{Na}$ Oficina de Expressão Dramática e Teatro pretendíamos (através de exercícios cooperativos, de exercícios/técnicas expressivas e sua aplicação, bem como a preparação de uma peça de teatro) atingir determinados objectivos como: 
- Potenciar, através de processos participativos, colaborativos e emancipativos, como a animação educativa aliada a práticas teatrais, o desenvolvimento pessoal e social dos futuros formadores.

- Sensibilizar para a importância da prática, nos processos de ensino-aprendizagem.

- Possibilitar aos formandos, através de linguagens múltiplas, uma participação alargada no seu próprio processo de desenvolvimento, de forma a tornarem-se mais independentes e seguros.

- Apostar numa educação/formação promotora de cidadãos activos e interventivos, abertos à mudança, à interacção, comunicação e cooperação, com capacidade critica e de análise de situações, tomada de decisões e resolução de problemas em situações imprevistas.

- Contribuir para a melhoria da prática pedagógica e do desempenho profissional dos formadores.

\subsection{Organização da Oficina de Expressão Dramática e Teatro}

A organização é fundamental para que os elementos que constituem um grupo possam criar e desenvolver os seus próprios projectos, objectivo essencial quando se trabalha no campo da Animação Educativa. Da adequada estruturação e organização de um projecto depende todo o sucesso do mesmo. Decidimos com esse intuito organizar o esquema da oficina de expressão dramática e teatro em redor de dois grandes eixos, o da percepção e o da expressão. Para o efeito dividimos a oficina em duas fases diferenciadas mas interrelacionadas e, em ambas, apoiamo-nos nas atitudes e nos valores, ingredientes inseparáveis do trabalho educativo que nos propúnhamos realizar.

$\mathrm{Na}$ 1a fase, a da percepção, valorizava-se a observação e a análise da realidade. Para o efeito realizavam-se nesta fase uma série de exercícios (actividades de introspecção, observação, desenvolvimento da percepção sensorial, integração no grupo, desenvolvimento do esquema corporal, ritmo, som, adaptações e improvisações), com a intenção de levar os formandos a 
descobrirem uma série de sensações, objectos e acções que estavam perto de si e em si e das quais nunca se tinham apercebido. Na $2^{\underline{a}}$ fase, a da expressão, procurava-se obter, de forma consciente e através da aprendizagem de uma série de técnicas, entre outras aquisições, o desenvolvimento da expressão pessoal, da capacidade criadora do formando, da experimentação e de estratégias para a resolução de problemas. Foi, pois, nesta fase que se desenvolveram os exercícios de representação de objectos e personagens, de jogo com objectos reais e imaginários, em suma, de experimentação.

\subsection{Actividades}

As actividades nascem do dinamismo dos grupos, concretizando-se em conjuntos de comportamentos organizados e em formas de acção estruturadas e sequencializadas. Na oficina de expressão dramática e teatro, as actividades nasceram do compromisso e da participação de todos os componentes do grupo, sem que, contudo, se pusesse em causa a liberdade pessoal de cada um, porque "é através das actividades que um grupo se estrutura e adquire coesão, se expressa e comunica, coloca os meios e realiza as tarefas que o levam a alcançar os objectivos. É ainda através delas que os indivíduos recriam a experiência, descobrem novas realidades, tomam consciência da sua estrutura e tarefas, em definitivo, crescem como pessoas e como grupos" (Viché, 1989: 73).

As actividades a desenvolver, constituídas por exercícios e jogos voltados para a descoberta/exploração, o desenvolvimento pessoal e social dos formandos e todo um processo de criação de uma peça de teatro, foram desenhadas em função dos recursos disponíveis, do tempo e do espaço de que se dispunha para as realizar com eficácia e de forma coerente com certos parâmetros, tais como: objectivos; nível de interesse; estrutura do grupo; situações; idade dos participantes e procuraram fomentar o trabalho cooperativo e produzir interacções comunicativas, ser significativas e motivar os formandos para a sua execução e, assim, atingirmos os objectivos que nos propúnhamos. De salientar que o projecto era efectivamente um projecto pedagógico, mas a apresentação de uma peça de teatro, inscrita num procedimento de desenvolvimento pessoal e social, podia surgir como desfecho do mesmo. 
As actividades, funcionando como forma de alcançar os objectivos propostos e como experiência para obter informação de forma a melhorar o processo, eram as premissas de todo o trabalho.

\subsection{Avaliação}

A avaliação reveste-se de grande importância ao concluir qualquer fase de um processo educativo e tem como papel verificar/analisar o percurso da acção educativa levada a cabo, dando-nos conta da evolução do processo de ensino/aprendizagem. Necessita, para isso, de instrumentos específicos adequados à área de aprendizagem.

$\mathrm{Na}$ educação a avaliação tem um papel deveras importante na formação do indivíduo, pois representa as suas conquistas ao longo das diferentes etapas. A avaliação contemplada no nosso plano incidiu, sobretudo, no desenrolar do processo levado a cabo na oficina, embora fossem também tidos em conta os resultados finais. Foi por isso uma avaliação qualitativa, conseguida através da observação constante da realidade e definiu-se segundo parâmetros contemplados na ficha formativa, em fichas retrospectivas e de auto-avaliação, que permitiam um controlo e feedback permanentes com vista a colmatar eventuais lacunas que pudessem surgir no processo e conhecer as opiniões dos formandos acerca das aprendizagens efectuadas, o que contribuiu para eventuais estratégias a adoptar posteriormente e foi importante para o desenvolvimento do espírito de autoavaliação dos formandos.

\subsection{Calendarização}

Ao configurarmos uma distribuição temporal ao design de um projecto estamos a imprimir-lhe organização quanto à forma como se irão suceder, complementar e coordenar as diferentes etapas do processo. No calendário deve igualmente mencionar-se os diferentes tipos de actividades, as suas características e duração. No entanto, esta planificação não deve ter um horário rígido para não desvirtuar o interesse e permitir inovações que possam surgir durante a realização de um projecto. Desenhar a calendarização de um projecto implica ainda estabelecer a data de início do projecto e o seu prazo de duração, que no caso do projecto em questão foi de um ano lectivo. 


\section{Implementação}

\section{Considerações prévias}

Um plano funciona como um instrumento metodológico de suporte das acções a desenvolver. É assim um instrumento precioso para o desenvolvimento de qualquer actividade formativa, porém, como refere AnderEgg (1997: 158), "formular um plano não é realizar um plano, do mesmo modo que projectar uma casa não é fazer uma casa". É preciso ter em conta um conjunto de imprevistos que poderão surgir durante a sua aplicação, que podem prejudicá-lo, serem uma oportunidade para o melhorar ou reforçar a sua aplicabilidade e eficácia.

\section{Fase de implementação}

No nosso relato não vamos descrever sequencialmente todas as actividades desenvolvidas na oficina, por se tornar num relato demasiado extenso e, por conseguinte, demasiado cansativo. Referimos, apenas, as actividades que melhor esclarecem o desenvolvimento do processo e que funcionaram como marcos importantes no desenvolvimento pessoal e social dos futuros educadores/professores envolvidos e que contribuíram eficazmente para os propósitos pretendidos.

As duas fases da oficina, dedicadas à percepção e à expressão, foram desenvolvidas segundo uma sequência lógica. Em ambas as fases foram desenvolvidos exercícios cooperativos que possibilitaram momentos ímpares de comunicação individual e grupal, coesão e cooperação, bem-estar físico e psíquico, fundamentais para o desenvolvimento de atitudes e valores, úteis, por conseguinte, para a modificação das relações. Estes exercícios funcionaram como base de apoio de toda a estrutura da oficina. Nesta fase levou-se igualmente a cabo um conjunto de sessões constituídas por exercícios e técnicas de expressão dramática, com o objectivo de libertar a capacidade criativa dos envolvidos. Os exercícios apresentaram-se seguindo uma escala ascendente de complexidade. Destacaram-se, entre eles, os exercícios: de reconhecimento do espaço, apresentação e desinibição; rítmicos; de respiração, relaxamento e concentração; de estimulação sensorial, pessoal e interpessoal; de expressão, consciência e plástica corporal; de articulação, dicção voz e expressão oral; de improvisação e 
dramatização. Por constituírem uma mais valia na área do teatro, abordámos em algumas das sessões da 1ํㅡ fase: a máscara e a caracterização; o mimo; o palhaço; a dança e as marionetas.

No final de cada sessão procedia-se à discussão e avaliação do trabalho desenvolvido. Preenchiam-se as fichas retrospectivas e/ou de autoavaliação, que funcionavam como registo e avaliação, para além de possibilitarem eventuais ajustes na planificação e fazer a análise qualitativa dos progressos alcançados.

$\mathrm{Na} 2^{\underline{a}}$ fase, para além do desenvolvimento de exercícios cooperativos a que já nos referimos, puseram-se em prática os conhecimentos adquiridos na fase anterior. Assim, as sessões desenvolvidas nesta fase foram dedicadas à aplicação das técnicas dadas e à preparação de uma peça de teatro, cujo texto foi criado pelos próprios formandos e que no final da oficina foi apresentada à comunidade, dando lugar a um Ciclo de Teatro destinado às crianças das diversas escolas do pré-escolar e ensino básico.

\section{Avaliação}

A avaliação do processo não se limitou à apreciação do trabalho no final de cada sessão, tratou-se efectivamente de uma avaliação contínua, formativa, baseada num acompanhar constante da natureza e qualidade da aprendizagem, que permitiu que fossemos acreditando, ao longo das diferentes fases do processo, que a Animação Educativa através de Práticas Teatrais, apoiada em metodologias activas como a Investigação-Acção, podia de facto motivar os futuros formadores para colaborarem activamente no seu próprio desenvolvimento pessoal e social.

A avaliação desenvolvida ao longo da acção caracterizou-se por uma constante relação de observação/reflexão/acção. A observação directa, a ficha de avaliação formativa e os registos foto-videográficos foram, portanto, vias que nos permitiram a recolha de dados pertinentes no sentido de um mais profundo conhecimento dos formandos.

Para melhor podermos aferir a eficácia da acção, no final da oficina aplicámos outro questionário e realizámos algumas entrevistas aos participantes na mesma, o que de forma menos formal nos permitiu obter mais informação, aprofundar e/ou consolidar a já adquirida, o que nos deu a 
conhecer as opiniões dos formandos sobre a totalidade da acção levada a cabo, as aprendizagens efectuadas e suas repercussões no plano pessoal, social e profissional de cada um e nos permitiu uma reflexão sobre a acção imprimida, facilitou a sua avaliação e possibilitou uma eventual reformulação de método e estratégias com vista à melhoria de futuras acções.

\section{Resultados retirados das respostas ao questionário e entrevista}

Transcrevemos, de seguida, parte dos resultados da análise de dados obtidos nas respostas ao questionário aplicado no final da oficina de expressão dramática e teatro. Assim, verificou-se que $56 \%$ dos inquiridos se identificaram mais com a fase de realização dos exercícios e aprendizagens de técnicas teatrais e $44 \%$ com o processo de preparação da peça de teatro. No tocante às actividades, $52 \%$ dos participantes referiram que gostavam de ter aprofundado mais os temas abordados; $28 \%$ gostavam de ter desenvolvido mais as técnicas de colocação de voz, a realização de máscaras e o teatro de sombras; $12 \%$ afirmaram estar satisfeitos com os temas abordados e $8 \%$ declararam que aprenderam imenso com a oficina. Relativamente à sua impressão, a partir da experiência vivida, em relação à Animação Educativa e ao Teatro, 16\% foram de opinião que animação educativa e teatro se complementam e são impulsionadores de desenvolvimento pessoal e social; $12 \%$ afirmaram que estas são ferramentas ideais para nos levar à fácil expressão, ao enriquecimento interior e a exteriorizar o que sentimos. Na opinião de $24 \%$ dos implicados na oficina, estas práticas incutem nos futuros formadores responsabilidade e respeito pelos outros; $4 \%$ sentiram que ganharam confiança e autonomia; $20 \%$ dos envolvidos no projecto sentiram que através da animação e do teatro se podem transmitir, de forma lúdica, normas, conhecimentos e desenvolver atitudes e valores; $12 \%$ sentiram que estas são ferramentas eficazes ao serviço da educação, na medida em que facilitam a aprendizagem e desenvolvem a criatividade e $12 \%$ referem que são excelentes auxiliares no desenvolvimento de capacidades e no relacionamento com as crianças. No tocante à mudança das suas relações com professores e colegas em função da oficina, $20 \%$ concordaram que as relações se tornaram mais sólidas e que passou a existir mais confiança e respeito entre todos. Percentagem idêntica 
(20\%) foi de opinião que se criaram novas amizades e se estabeleceram relações mais fortes; $16 \%$ afirmam que se reforçou a amizade, a responsabilidade, o companheirismo, a solidariedade e a entreajuda; $20 \%$ frisaram que se aproximaram mais dos professores e que as relações com os colegas melhoraram bastante; $8 \%$ mencionam que ganharam à vontade para falar com as pessoas; $4 \%$ que se tornaram menos introvertidos e mais sociáveis; $8 \%$ que aprenderam a ser mais tolerantes, compreensivos e aprenderam a escutar os outros e, por último, 4\% generalizam, referindo apenas que melhoraram em muitos aspectos.

Relativamente ao facto das aprendizagens conseguidas se poderem repercutir na sua prática pedagógica obtivemos os seguintes resultados: $16 \%$ mencionaram que os conhecimentos adquiridos na oficina foram logo aplicados no desenvolvimento pessoal e social das crianças, durante as práticas pedagógicas do estágio; $52 \%$ afirmaram que isso iria certamente acontecer na intervenção com os seus educandos, sobretudo ao nível da responsabilidade, flexibilidade, criatividade e mudança de atitudes; $12 \%$ foram de opinião que o espírito de grupo que desenvolveram ia reflectir-se na sua relação com as crianças e $8 \%$ referiram estar mais motivados para desenvolverem actividades com as crianças.

No tocante à entrevista informal que fizemos obtivemos respostas tais como: "Na oficina aprendi a conhecer-me melhor, a lidar com os outros, a saber ouvir e respeitar o outro, o que no mundo actual é bastante importante."; "Esta experiência proporcionou uma maior união e colaboração entre todos e todos modificámos um pouco para melhor."; "Na própria turma os elementos do grupo sentiram-se mais unidos, porque nos conhecíamos melhor, mas melhorámos também o nosso relacionamento com os restantes colegas."; "Não ouvi ninguém dizer que não gostou desta experiência, que acima de tudo, nos ajudou a crescer. Além disso, pessoalmente ajudou-me a desinibir, já que tinha um certo receio em falar. Sinto que ganhei auto-controlo e segurança."

\section{Reflexões conclusivas}

Sentimos ao longo da acção, e por razões várias, a necessidade de pontuais acertos e algumas adaptações a que a prática pedagógica 
(suportada pela planificação elaborada) esteve sempre aberta. Esta forma de actuar permitiu que os resultados que retirámos da experiência evidenciassem e permitissem formular, de forma clara, que a Animação Educativa aliada à prática teatral se constitui como terreno de aprendizagem capaz de mobilizar os Profissionais de Educação para uma resposta educativa às necessidades actuais, na medida em que contribui para melhorar a sua forma de ser, sentir e agir e que quando utilizada, como meio de desenvolvimento pessoal e social de futuros formadores, melhora a Educação e a Formação, é um seu complemento, uma optimização. É, sobretudo, uma componente essencial ao desenvolvimento da capacidade que o ser humano tem de se ajustar e reajustar continuamente ao longo da vida.

\section{Referências}

AGUSTÍ, Xavier B. (1993). Reflexividad-impulsividad y autorregulación: sus aplicaciones en contextos educativos. Revista Educação, 1, pp. 85-102.

ANDER-EGG, Ezequiel (1997). Metodologias de Acción Social. Madrid: Instituto de Ciencias Sociales Aplicadas.

ALCÁNTARA, Joaquim A. (1998). Como Educar as Atitudes. Lisboa: Plátano.

ALVES, José M. (2003). A reforma. Correio da Educação, no 161, p. 1.

BARBOSA, Manuel, coord. (1999). Olhares Sobre Educação, Autonomia e Cidadania. Braga: Universidade do Minho.

BARBOSA, Manuel G., Ed. (2001). Educação do Cidadão. Recontextualização e Redefinição. Braga: Edições APPACDM.

BELTRÃO, Luísa \& NASCIMENTO, Helena (2000). O Desafio da Cidadania na Escola. Lisboa: Editorial Presença.

BELL, Judith (1997). Como Realizar um Projecto de Investigação. Lisboa: Gradiva.

BELTRÁN, Leonor (2000). Globalização e reeducação expressivo-artística: e pela asa do sonho eu me crio... In AAVV, Educação pela Arte. Lisboa: Livros Horizonte, pp. $127-142$.

BOLÍVAR, António (2000). A educação em valores: O que aprendemos com o esboço e o seu desenvolvimento curricular em Espanha? In F. Trilla (coord.), Atitudes e Valores no Ensino. Lisboa: Instituto Piaget, pp. 123-170.

CABRAL, António (2001). O Jogo no Ensino. Lisboa: Notícias.

CUNHA, Maria José S. (2000). Animação educativa e teatro: práticas construtoras de saberes. In Comunicações. II Jornadas Internacionais de Animação Sociocultural. Chaves: UTAD, pp. 86-88. 
DIAS, José R. (2002). Prefácio. In E. O. Medeiros, A Filosofia na Educação Secundária: Uma Reflexão no Contexto da Reforma Curricular e Educativa. Ponta Delgada: Universidade dos Açores, pp. 17-19.

FERNANDES, Preciosa et al. (2001). Uma Formação em Círculo. Lisboa: IIE.

FONSECA, António M. (1994). Personalidade, Projectos Vocacionais e Formação Pessoal e Social. Porto: Porto Editora.

FONSECA, António M. (2001). Educar para a Cidadania. Motivações, Princípios e Metodologias. Porto: Porto Editora.

FREIRE, Paulo (1972). Pedagogia do Oprimido. Rio Janeiro: Paz e Terra.

GRÁCIO, Rui (1995). Obra Completa. Lisboa: Fundação Calouste Gulbenkian.

GRILO, Marçal (2002). Desafios da Educação. Ideias para uma Política Educativa no Século XXI. Lisboa: Oficina do Livro.

HERNANDO, Maria Á. (1999). Estrategias para Educar en Valores. Madrid: CCS.

JACINTO, Deniz (1991). Teatro I. Porto: Lello e Irmão Editores.

KEMMIS, Steve \& MACTAGGART, Robin (1988). Cómo Planificar la Investigación Acción. Barcelona: Laertes.

LAGUNA, Encarna (1995). Como Desarrollar la Expresion a Traves del Teatro. Barcelona: CEAC.

MARTÍNEZ, Roca G. (2001). Valores Humanos y Desarrollo Personal. Barcelona: CISSPRAXIS.

MORIN, Edgar (2001). O Desafio do Século XXI. Religar os Conhecimentos. Lisboa: Instituto Piaget.

NÓVOA, António (1993). Os desafios da educação e as respostas do teatro. In C. Fragateiro (coord.), Da Expressão Dramática ao Jogo Teatral. Aveiro: Unave, pp. 9-14.

PAIXÃO, Maria Lourdes L. (2000). Educar para a Cidadania. Lisboa: Lisboa Editora.

PINTASSILGO, Joaquim (1998). República e Formação de Cidadãos. A Educação Cívica nas Escolas Primárias da Primeira República Portuguesa. Lisboa: Edições Colibri.

PRAIA, Maria (1991). Desenvolvimento Pessoal e Social. Porto: ASA.

QUINTAS, Sindro F. (2002). Animación sociocultural y educación en valores. In Comunicações. II Jornadas Internacionais de Animação Sociocultural. Chaves: UTAD, pp. 103-110.

SAVATER, Fernando (1997). El Valor de Educar. Barcelona: Editorial Ariel.

SERRANO, Glória P. (1999). Elaboración de Proyectos Sociales. Casos Prácticos. Madrid: Narcea.

SIMÃO, José V.; SANTOS, Sérgio M. \& COSTA, António A. (2002). Ensino Superior: uma Visão para a Próxima Década. Lisboa: Gradiva.

SOARES, Mário (1997). Mensagem de sua Ex. ․ㅡ o Presidente da República ao II congresso da educação pluridimensional e da escola cultural. In M. F.Patrício (org.), Escola Cultural e os Valores. Porto: Porto Editora, pp. 15-18. 
UCAR, Xavier (1992). La Animación Sociocultural. Barcelona: CEAC.

VENTOSA, Victor J. (1995). Guía de Recursos para la Animación. Madrid: CCS.

VENTOSA, Victor J. (1997). Intervención Socioeducativa. Madrid: CCS.

VICHÉ, Mário (1989). El Voluntario en la Acción Sociocultural. Madrid: Popular.

ZABALZA, Miguel Angel B. (1998). Planificação e Desenvolvimento Curricular na Escola. Lisboa: Asa.

EDUCATIONAL ANIMATION IN SOCIAL AND PERSONAL DEVELOPMENT OF FUTURE EDUCATORS: A THEATRICAL PRACTICE CENTERED APPROACH

\begin{abstract}
In this article, based on a study developped in extra-curricular context with preservice kindergarten and elementary school teachers, we intend to focus on the role of a still ill-explored issue in the context of initial formation, the theme of educational animation, combined with theatrical practice. The process that lead to it is briefly described, the results are presented and its values are discussed accordingly.
\end{abstract}

Keywords

Development; Formation; Animation; Practice 
L'ANIMATION EDUCATIVE DANS LE DEVELOPPEMENT PERSONNEL ET SOCIAL

DE FUTURS EDUCATEURS: UN ABORDAGE CENTRE SUR LA PRATIQUE THÉATRALE

Résumé

Dans cet article, nous procurons, à partir d'une étude réalisée en contexte extra-curriculaire avec de futurs éducateurs de l'école maternelle et primaire, verser sur le rôle d'un object d'étude encore peu exploré en contexte de formation initiale, celui de l'animation éducative alliée à des pratiques théatrales, en décrivant sommairement le processus qui nous y a conduit, en présentant les résultats et en analysant ses valeurs.

Mots-clé

Développement; Formation; Animation; Pratiques

Recebido em Maio, 2006 Aceite para publicação em Abril, 2008

Toda a correspondência relativa a este artigo deve ser enviada para: Maria José dos Santos Cunha, Rua do Poço no 47, 5400-450 Chaves, Portugal. Telf.: 276326677, Telem.: 965079830, Email: mjscunha@net.sapo.pt 